\title{
Temporomandibular disorder is associated with a serotonin transporter gene polymorphism in the Japanese population Kiyomi Ojima ${ }^{1}$, Nagaoki Watanabe ${ }^{2}$, Naoko Narita ${ }^{1}$ and Masaaki Narita*1
}

Address: ${ }^{1}$ Graduate School Human Sciences, University of Tsukuba, Ibaraki, Japan and ${ }^{2}$ Department of Oral and Maxillofacial Surgery, Kawaguchi Municipal Medical Center, Saitama, Japan

Email: Kiyomi Ojima - s010741@yahoo.co.jp; Nagaoki Watanabe - wata-n@db4.so-net.ne.jp; Naoko Narita - nnarita@koshigaya.bunkyo.ac.jp; Masaaki Narita* - narita_m@doc.medic.mie-u.ac.jp

* Corresponding author

Published: 10 January 2007

BioPsychoSocial Medicine 2007, I:3 doi:10.1 I86/175I-0759-1-3

This article is available from: http://www.bpsmedicine.com/content/I/I/3

(C) 2007 Ojima et al; licensee BioMed Central Ltd.

This is an Open Access article distributed under the terms of the Creative Commons Attribution License (http://creativecommons.org/licenses/by/2.0), which permits unrestricted use, distribution, and reproduction in any medium, provided the original work is properly cited.
Received: 17 August 2006

Accepted: 10 January 2007

\begin{abstract}
Aims: Recent genetic studies have linked serotonin-related genetic polymorphisms with diverse disorders characterized by functional somatic symptoms, including chronic fatigue syndrome, irritable bowel syndrome, and premenstrual dysphoric disorder.
\end{abstract}

Methods: We investigated three serotonin-related genetic polymorphisms by screening genomic DNA of 36 temporomandibular disorder (TMD) patients.

Results: A significant increase of longer alleles ( $\mid$ and $x l)$ was found in the TMD patients compared to the controls both by the genotype-wise and the allele-wise analyses (both $p<0.0$ I by $\chi^{2}$ test and Fisher's exact test).

Conclusion: Genetic factors that involve the serotonergic system may play a role in the pathogenesis of TMD.

\section{Findings}

Temporomandibular disorder (TMD) is a heterogeneous group of disorders affecting the temporomandibular joints, the masticatory muscles, or both. TMD generally develops orofacial pain as an initial symptom, and approximately $10 \%$ of all orofacial pain patients who complain of localized myalgia or tenderness in the masticatory muscles for more than one month are generally diagnosed as TMD [1,2]. TMD is often comorbid with other psychosomatic symptoms such as sleep disorder, headache, fatigue, and depression, which are characterized as functional somatic syndromes (FSS) $[3,4]$. The concept of FSS is a multidimensional classification based on clinical features, and it incorporates a variety of syndromes such as chronic fatigue syndrome (CFS), irritable bowel syndrome (IBS), premenstrual dysphoric disorder
(PMDD), TMD, and non-cardiac chest pain. Although the physiological function of neurotransmitter serotonin (5hydroxytryptamine, 5-HT) accounts for most of these common symptoms of FSS, the concept itself has been controversial to date because of the lack of a biological etiology to explain the mechanism of FSS [5]. The 5-HT neuronal system regulates diverse physiologic functions including sleep, respiration, appetite, pain, motor function, cognition, sexual activity, as well as emotions such as mood and anxiety. Polymorphic study within 5-HT related genes are reported to be associated with numerous disorders and illness by our group and others, including CFS $[6]$, IBS $[7,8]$, and PMDD $[9,10]$, suggesting a relevance of 5-HT neuronal dysfunction to the disease categorized as FSS. Therefore, we screened three 5-HT related 
genomic DNA polymorphisms in patients with TMD, another disorder categorized as FSS.

Thirty-six patients (mean age; $45.3+/-16.7$ years old, 5 males and 31 females) at the Department of Oral and Maxillofacial Surgery of Kawaguchi Municipal Medical Center were enrolled in the study. Patients were diagnosed as TMD by chronic and localized myalgia and tenderness to palpation that persisted for more than one month, basically according to the literatures describing research diagnostic criteria for TMD. (Anastassaki and Magnusson 2004). For controls, 119 healthy volunteers (mean age $26.4+/-8.9$ years old, 49 men and 70 women) were recruited to the study. Written informed consent was obtained prior to the study, and the study was approved by the ethics committees of Kawaguchi Municipal Medical Center and the University of Tsukuba.

Genomic DNA was extracted from the whole blood of every participant using a Genomic DNA isolation reagent (E.Z.N.A Blood DNA Kit?, Omega Bio-tek, GA, USA). The extracted DNA was amplified by polymerase chain reaction (PCR) to detect serotonin-related polymorphisms. To avoid bias in the observation, all DNA samples were tested without sample information until all data was obtained.

For serotonin transporter protein promoter polymorphism (5-HTTLPR) analysis, extracted DNA was amplified by polymerase chain reaction (PCR), basically according to the method of Lesch et al. [11]. Oligonucleotide primers flanking the 5-HTTLPR and corresponding to the nucleotide positions-1416 to -1397 (5'-GGCGTTGCCGCTCTGAATGC) and -910 to 88 (5'-GAGGGACTGAGCTGGACAACCAC) of the 5-HTT gene 5'-flanking regulatory region were used to generate 484(s)-, 528(l)-, 572 or $616(\mathrm{xl})$ - bp fragments.

For 5HTTintron2 variable-number-tandem-repeat (VNTR), oligonucleotide primers set within intron 2 to detect the VNTR region, 5'-GTCAGTATCACAGGCTGCGAG-3' and 5'-TGTTCCTAGTCTTACGCCAGTG-3' were used as described by Collier et al [12]. The amplified products were either 250 or 284 bp fragments, corresponding to the 9 and 11 repeat-containing alleles, respectively.

For -1438 G/A serotonin 2A receptor (5HT 2AR), oligonucleotide primers set within the 5HT 2A receptor gene 5'flanking promoter region, 5'-AAGCTGCAAGGTAGCAACAGC-3' and 5'-AACCAACTTATTTCCTACCAC-3' were used as previously described by Collier et al [13], followed by digesting the amplified 468 bp products with Msp I (Takara bio inc, Japan), which cuts the $-1438 / G$ allele into two fragments of 244 and 224 bp. The end products were either $468 \mathrm{bp}$, corresponding to $-1438 / \mathrm{A}$ allele, or 244 and 224 bp corresponding to $-1438 / \mathrm{G}$ allele.

All PCR amplification was carried out in a final volume of $20 \mu \mathrm{l}$ consisting of $50 \mathrm{ng}$ of genomic DNA, $2.5 \mathrm{mM}$ deoxyribonucleotides, $20 \mathrm{pmol}$ of forward and reverse primers, $10 \mathrm{mM}$ tris/ $\mathrm{HCl}$ (pH 8.3), $50 \mathrm{mM} \mathrm{KCl}, 1.5 \mathrm{mM} \mathrm{MgCl}_{2}$, and $1 \mathrm{U}$ of Taq DNA polymerase (Takara bio inc, Japan). Annealing was carried out at $61^{\circ} \mathrm{C}$ for $30 \mathrm{~s}$, extension at $72^{\circ} \mathrm{C}$ for $1 \mathrm{~min}$, and denaturation at $95^{\circ} \mathrm{C}$ for $30 \mathrm{~s}$ for 35 cycles. PCR products were visualized by $2 \%$ agarose gel electrophoresis followed by ethidium bromide staining.

Statistical analysis was done for comparisons of the TMD and the control groups. $\chi^{2}$ test (2-tailed) was used for between group comparisons of the genotype distribution and allele frequency of gene polymorphism. Fisher's exact test was also used to examine the $p$ value. $P$ values less than 0.05 were considered to be statistically significant.

Table 1 shows a summary of the genotype distribution analysis of 5HTTLPR. Genotypes including longer alleles ( $l$ and $\mathrm{xl}$ ) were statistically increased in the TMD group compared to control group ( $p=0.0079$ by Pearson's $\chi^{2}$ test and $p=0.0044$ by Fisher's exact test) (upper panel). When 5-HTTLPR was analyzed allele-wise, the longer alleles were found in $14.3 \%$ (13.9\% l allele and $0.4 \%$ xl allele, respectively) of the control subjects (Table 1, lower panel). Statistical analysis revealed a significant difference between the patient and control groups ( $p=0.0027$ by Pearson's $\chi^{2}$ test and $p=0.0019$ by Fisher's exact test). 5HTTintron2VNTR or $-1438 \mathrm{G} / \mathrm{A} 5 \mathrm{HT} 2 \mathrm{AR}$ polymorphic analysis was also performed, however, no significant difference was found between the patients and controls by either genotype distribution analysis or allele frequency analysis (data not shown).

The 1 allele of 5-HTTLPR, which was the most frequently observed in the TMD patients in the present study, is supposed to retain higher transcriptional activity than the $S$ allele [11]. This may result in a lower concentration of 5HT in the extracellular space, namely, active 5-HT. To date, a number of diseases have been proved to be associated with 5-HTTLPR. For instance, the longer alleles (l and $\mathrm{xl}$ ) were demonstrated to be significantly increased in the victims of sudden infant death syndrome (SIDS) [14-16]. This fact may explain the pathophysiology of SIDS, which has long been suspected to be a defect in the arousal or sleep mechanisms in the brainstem regulated by the serotonergic neuronal system. Anxiety trait [11], mood disorder $[17,18,19,20]$, autism $[19,21]$, and eating disorders have likewise been investigated in an attempt to show an association with 5-HTTLPR [22, 23], although much remains to be clarified and some of the results are controversial. 
Table I: Genotype distribution data (upper panel) and allele frequency data (lower panel) for 5HTTLPR from TMD patients and controls.

\begin{tabular}{|c|c|c|}
\hline genotype & TMD & control \\
\hline 5HTTLPR & $n=36$ & $n=119$ \\
\hline$s / s$ & 17 (47.2\%) & 87 (73.1\%) \\
\hline$s / l$ & $14(38.9 \%)$ & $29(24.4 \%)$ \\
\hline $\mathrm{I} / \mathrm{I}$ & $4(1 \mathrm{I} .1 \%)$ & $2(1.7 \%)$ \\
\hline$s / x \mid$ & I (2.8\%) & $\mathrm{I}(0.8 \%)$ \\
\hline \multicolumn{3}{|l|}{$P$ value } \\
\hline Pearson's $\chi^{2}$ test & 0.0079 & \\
\hline Fisher's exact test & 0.0044 & \\
\hline allele & TMD & control \\
\hline 5HTTLPR & $\mathrm{n}=72$ & $n=238$ \\
\hline s & $49(68.1 \%)$ & 204 (85.7\%) \\
\hline I & $22(30.5 \%)$ & $33(13.9 \%)$ \\
\hline$x \mid$ & I (I.4\%) & $\mathrm{I}(0.4 \%)$ \\
\hline \multicolumn{3}{|l|}{$P$ value } \\
\hline Pearson's $\chi^{2}$ test & 0.0027 & \\
\hline Fisher's exact test & 0.0019 & \\
\hline
\end{tabular}

The definition of FSS allows for a substantial overlap in the symptoms of syndromes such as CFS, IBS, and fibromialgia (FM). Therefore, patients may have more than one diagnosis, depending on the expertise of the physician they visit. It is more persuasive that FSS may be caused by a dysfunction of central nervous system, especially of the 5-HT neuronal system, rather than by the abnormalities in specific organ systems. This may explain the multiple symptoms of FSS and the frequent co-morbidities of emotional disorders such as anxiety disorder and major depression.

Some replicated results of challenge tests with CFS patients have been reported, including enhanced prolactin response to a selective 5-HT agonist, D-fenfluramine. Since the interaction between the hypothalamo-pituitaryadrenal axis and the 5-HT system is probably mediated partially by the 5-HT receptors in the hippocampus, this result indicates a hypofunction of the 5-HT system and/or a hypersensitivity of the 5-HT receptors in the brain of CFS patients [24, 25, 26]. Genetic association among FSS diseases have also been reported. For example, longer alleles ( 1 and $x / 1$ ) are frequent in CFS [6], s/s genotype was increased in diarrhea predominant IBS [7], whereas the $1 /$ 1 genotype was increased in constipation type IBS $[7,8]$. PMDD is also reported to be associated with 5HTTLPR [9]. Although the increased allele is different depending on the disease, these reports indicate that serotonergic dysfunction might be involved in the pathogenesis of these diseases because the polymorphism is functional.
Our results clearly show a significant association between the longer alleles ( 1 and $\mathrm{xl}$ ) of 5HTTLPR and the TMD group. This facts suggest to us that 1 ; 5HTTLPR could be further exploited as a diagnostic tool for TMD out from other orofacial pain diseases. 2; the pathogenesis of TMD is thought to be significantly associated with serotonergic neuronal dysfunction, which is in common with other disorders as FSS. To our knowledge, this is the first reported genetic linkage to TMD, and it emphasizes the '5HT system dysfunction hypothesis' when considering the etiology of the disease. Considering TMD to include overlapping FSS syndromes such as CFS and IBS, we can postulate that individuals carrying the longer alleles are more susceptible to FSS than individuals with the short allele, because of the relative hypofunction of the 5-HT system due to a lower 5-HT concentration in the extracellular space, compared to the ones with the short allele. However, we have to be very careful in our evaluation of these findings because of the extremely small sample size, even though the $p$ value is small. Further independent studies will be necessary to confirm the present data.

\section{Authors' contributions}

KO carried out the molecular genetic studies and performed the statistical analysis. NW performed clinical diagnosis. NN participated in the design of the study and drafted the manuscript. MN conceived the study and participated in its design and coordination and helped to draft the manuscript. All authors read and approved the final manuscript. 


\section{Acknowledgements}

We thank Kyoko Matsui (University of Tsukuba, Ibaraki, Japan) for her technical support. This work was supported by Grants-in-Aid for Scientific Research (C) of the Japan Society for the Promotion of Science, and the Special Coordination Funds of the Ministry of Education, Culture, Sports, Science, and Technology of the Japanese Government.

\section{References}

I. Barsky AJ, Borus JF: Functional somatic syndromes. Annals of Internal Medicine 1999, 130:910-921.

2. Clemenger K: Functional somatic syndromes. Annals Of Internal Medicine 2000, I32:327-328.

3. Narita M, Nishigami N, Narita N, Yamaguti K, Okado N, Watanabe $\mathrm{Y}$, Kuratsune $\mathrm{H}$ : Association between serotonin transporter gene polymorphism and chronic fatigue syndrome. Biochemical And Biophysical Research Communications 2003, 3 I I:264-266.

4. Praschak-Rieder N, Willeit M, Winkler D, Neumeister A, Hilger E, Zill P, Hornik K, Stastny J, Thierry N, Ackenheil M, Bondy B, Kasper $S$ : Role of family history and 5-HTTLPR polymorphism in female seasonal affective disorder patients with and without premenstrual dysphoric disorder. Eur Neuropsychopharmacol 2002, I 2:129-134.

5. Melke J, Westberg L, Landen M, Sundblad C, Eriksson O, Baghei F, Rosmond R, Eriksson E, Ekman A: Serotonin transporter gene polymorphisms and platelet $[3 \mathrm{H}]$ paroxetine binding in premenstrual dysphoria. Psychoneuroendocrinology 2003, 28:446-458.

6. Anastassaki A, Magnusson T: Patients referred to a specialist clinic because of suspected temporomandibular disorders: a survey of 3194 patients in respect of diagnoses, treatments, and treatment outcome. Acta Odontol Scand 2004, 62:183-192.

7. Lesch KP, Bengel D, Heils A, Sabol SZ, Greenberg BD, Petri S, Benjamin J, Muller CR, Hamer DH, Murphy DL: Association of anxiety-related traits with a polymorphism in the serotonin transporter gene regulatory region. Science 1996, 274:|527-|53|.

8. Collier DA, Arranz MJ, Sham P, Battersby S, Vallada H, Gill P, Aitchison KJ, Sodhi M, Li T, Roberts et : The serotonin transporter is a potential susceptibility factor for bipolar affective disorder. Neuroreport 1996, 7:1675-1679.

9. Collier DA, Arranz MJ, Li T, Mupita D, Brown N, Treasure J: Association between 5-HT2A gene promoter polymorphism and anorexia nervosa. Lancet 1997, 350:412-4I2.

10. Kunugi H, Hattori M, Kato T, Tatsumi M, Sakai T, Sasaki T, Hirose T, Nanko S: Serotonin transporter gene polymorphisms: ethnic difference and possible association with bipolar affective disorder. Molecular Psychiatry 1997, 2:457-462.

II. Meira-Lima I, Michelon L, Cordeiro Q, Cho HJ, Vallada H: Allelic association analysis of the functional insertion/deletion polymorphism in the promoter region of the serotonin transporter gene in bipolar affective disorder. J Mol Neurosci 2005, 27:219-224

12. Betancur C, Corbex M, Spielewoy C, Philippe A, Laplanche JL, Launay JM, Gillberg C, Mouren-Simeoni MC, Hamon M, Giros B, Nosten-Bertrand $M$, Leboyer $M$ : Serotonin transporter gene polymorphisms and hyperserotonemia in autistic disorder. Molecular Psychiatry 2002, 7:67-7I.

13. Ogilvie AD, Battersby S, Bubb VJ, Fink G, Harmar AJ, Goodwim GM, Smith CA: Polymorphism in serotonin transporter gene associated with susceptibility to major depression. Lancet 1996, 347:73I-733.

14. Surtees PG, Wainwright NW, Willis-Owen SA, Luben R, Day NE, Flint J: Social Adversity, the Serotonin Transporter (5HTTLPR) Polymorphism and Major Depressive Disorder. Biol Psychiatry 2005.

15. Yirmiya N, Pilowsky T, Nemanov L, Arbelle S, Feinsilver T, Fried I, Ebstein RP: Evidence for an association with the serotonin transporter promoter region polymorphism and autism. American Journal of Medical Genetics 200I, I 05:38I-386.

16. Fumeron F, Betoulle D, Aubert R, Herbeth B, Siest G, Rigaud D: Association of a functional 5-HT transporter gene polymorphism with anorexia nervosa and food intake. Molecular Psychiatry 2001, 6:9-10.

17. Gorwood P: Eating disorders, serotonin transporter polymorphisms and potential treatment response. American Journal of
Pharmacogenomics: Genomics-Related Research In Drug Development And Clinical Practice 2004, 4:9-I7.
Publish with Biomed Central and every scientist can read your work free of charge

"BioMed Central will be the most significant development for disseminating the results of biomedical research in our lifetime. "

Sir Paul Nurse, Cancer Research UK

Your research papers will be:

- available free of charge to the entire biomedical community

- peer reviewed and published immediately upon acceptance

- cited in PubMed and archived on PubMed Central

- yours - you keep the copyright
Biomedcentral 